\title{
BRCA1 NM_007294.3:c.68_69delAG
}

National Cancer Institute

\section{Source}

National Cancer Institute. BRCA1 NM 007294.3:C.68 69delAG. NCI Thesaurus. Code C131473.

A deletion of the two nucleotides in positions 68 and 69 from the coding sequence of the BRCA1 gene. 